\title{
Research on BIM information evaluation of dynamic sustainable green construction of urban deep foundation pit
}

\author{
Hong Tang, Dan Xiao, Yu Huang, Jiaqi Chen, and Mingwei Qian* \\ Wuhan University of Science and Technology, China
}

\begin{abstract}
The existing green construction evaluation lacks dynamic nature. Based on the characteristics of urban deep foundation pit construction, PDCA cycle theory gives the dynamic evaluation index weight based on OWA operator, and establishes a dynamic evaluation model. BIM information technology is used to build a platform and Wuhan Yangtze River Shipping Center proves the scientific nature of dynamic evaluation.
\end{abstract}

\section{Introduction}

The continuous implementation of the concept of sustainable development puts forward higher requirements for green construction. At present, the common method to promote green construction is to adopt scientific evaluation method. Tian Tian ${ }^{[1]}$ has established green construction evaluation system with 22 primary indicators of green construction. Wang $\mathrm{Fu}{ }^{[2]}$ adopts scientific negative entropy theory and green construction with quantitative factors. Li Xiang ${ }^{[3]}$ uses Shapley empowerment and grey clustering theory, and conducted green construction evaluation with campus building as the object. It can be seen that the evaluation theory research is relatively mature, but the promotion effect of green construction is not good.

Through the investigation of the construction enterprise, it is learned that there are many deficiencies in the current green construction evaluation, among which the biggest problem is that the evaluation method is fixed. The supervision department conducts a one-time evaluation after the completion of the project, ignoring the self-optimization in the process of the construction enterprise, which makes the evaluation a mere formality. Therefore, it is particularly important to establish dynamic evaluation. Suhuan ${ }^{[4]}$ has established green construction evaluation framework based on PDCA cycle theory and improved the traditional evaluation process; Hong Yanyan ${ }^{[5]}$ uses CATWOE analysis method to establish green construction physics-reason-human theory (WSR) dynamic evaluation process.

As is known to all, there are many contents of green construction evaluation. If dynamic evaluation should be adopted, how to solve the real-time collection and timely evaluation of evaluation information is an important link in the transition of dynamic evaluation theory to reality. It is a good solution to adopt appropriate information means. Ma Rongmin ${ }^{[6]}$ has

* Corresponding author: 1120812845@qq.com 
proposed the green construction information system based on BIM technology from the management perspective; Liu Zhao Haomin ${ }^{[7]}$ analyzes the green construction content and establishes an application process running through the information.

To sum up, in order to promote green construction better and sustainable development, it is particularly critical to establish dynamic evaluation mode, and needs to realize the transition of information technology. Through comparative research, the construction process of urban deep foundation pit project has a great impact on the environment, and problems in any link of the process will lead to irreversible consequences, so it is urgent to establish a scientific dynamic evaluation mode. Therefore, this paper chooses the urban deep foundation pit project as the research object, determines the evaluation index through the expert questionnaire, and uses the OWA operator to optimize the index weight to establish a scientific evaluation system. On this basis, PDCA circular theory and BIM information technology are used to complete the construction of dynamic green construction information evaluation platform.

\section{Establishment of PDCA dynamic evaluation mode}

PDCA(Plan-Implementation-Inspection-Action) Circular Theory is a quality control mode that is a continuous advancing process, linking the dynamic work of various objectives and continuously optimizing the improvement. This is consistent with the dynamic sustainable evaluation model of Green construction.

Referring to the existing green construction evaluation standards, the objects evaluated are water saving, material saving, land saving, energy saving and environmental protection. These objects cannot be separated from the specific construction management plan on the site, which is also an important means for the independent optimization of construction enterprises. Construction management can be used as the "plan" link in the PDCA cycle, while the above objects are the "implementation" link, the established evaluation system is the "inspection" link, and the subsequent work based on the evaluation results is the "action" link. Thus build a dynamic evaluation process, as shown in Figure 1.

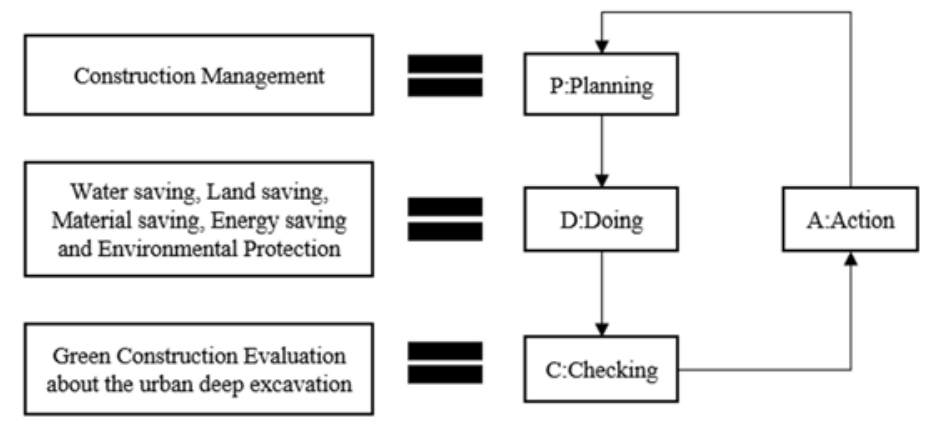

Fig. 1. PDCA Circulation Mode of Green Construction Evaluation of Urban Deep Foundation Pit.

\section{Establishment of the green construction evaluation model for urban deep foundation Pit}

\subsection{Establishment of the evaluation index system}

The construction process of urban deep foundation pit causes great damage to the environment, and the index weight of the existing evaluation standards cannot be directly 
applied. At the same time, the evaluation index system should meet the principles of operability, pertinence, scientific and practical nature. On the basis of grasping the existing standards and norms, summarize the key points of the green construction of the deep foundation pit project, select and improve the index system through the expert questionnaire survey, and establish a scientific index system as shown in Table 1.

Table 1. Green construction evaluation system of urban deep foundation Pit.

\begin{tabular}{|c|c|l|}
\hline Target layer & Code-layer & \multicolumn{1}{|c|}{ Subcriterion layer } \\
\hline \multirow{1}{*}{$\begin{array}{c}\text { Environmental } \\
\text { Protection, } \\
\text { A 1 }\end{array}$} & $\begin{array}{l}\text { Cultural relic protection and surrounding environment } \\
\text { coordination A11, noise control A12, dust control A13, mud } \\
\text { control and treatment A14, waste water pipe control A15 }\end{array}$ \\
\cline { 2 - 4 } struction & $\begin{array}{c}\text { Construction } \\
\text { Management A } \\
\text { evaluation }\end{array}$ & $\begin{array}{l}\text { Safety and Management System A21, Green Technology } \\
\text { Application and Innovation A22, Dynamic Management and } \\
\text { Information Construction A23, Enterprise and Individual } \\
\text { Qualification Review Report A24 }\end{array}$ \\
\cline { 2 - 4 } & $\begin{array}{c}\text { Power-saving } \\
\text { A 4: }\end{array}$ & $\begin{array}{l}\text { Building Waste Fertilizer Recycling and Utilization of A31, } \\
\text { Section Material Design A32, Equipment Materials and } \\
\text { Selection A33 }\end{array}$ \\
\cline { 2 - 4 } & $\begin{array}{l}\text { Drainage system A41, water supply system A42, new water } \\
\text { saving new technology and new equipment A43, domestic } \\
\text { office water A44 }\end{array}$ \\
\cline { 2 - 4 } & $\begin{array}{l}\text { Energy-efficien } \\
\text { t A 5 }\end{array}$ & $\begin{array}{l}\text { Energy Saving New Technology New Equipment A51, } \\
\text { Equipment Maintenance and Inspection A52, Living Office } \\
\text { Energy Saving A53 }\end{array}$ \\
\cline { 2 - 4 } & $\begin{array}{l}\text { Ground } \\
\text { Section A 6 }\end{array}$ & $\begin{array}{l}\text { Impact of foundation pit excavation on surrounding land A 61, } \\
\text { foundation pit layout and construction scheme optimization } \\
\text { A62, green land and land resources A63 }\end{array}$ \\
\hline
\end{tabular}

\subsection{Determination of the index weight}

The scientific nature of the index weight is the key to whether the green construction evaluation can reflect the green construction level of the project. Because the AHP level analysis method enlarges the influence of the expert subjective preference on the index weight, this paper optimizes the index weight through the OWA operator. Weight calculation using expert questionnaire survey, expert group from wuhan city bureau survey and design and technology, urban construction bureau, China university of geology, China coal construction association, wuhan survey and design co., LTD., central south construction design institute co., LTD., etc., zhongjian three bureau, and other six units, covering the university, construction unit, design unit, survey unit, research institute of the senior experts in the industry.

The $P$-bit expert scored the importance of $\mathrm{n}$ index items, obtained the evaluation index importance data, and obtained the index weight distribution matrix $\mathrm{W}_{0}$ after the AHP method.

$$
W_{0}=\left[\begin{array}{cccc}
w_{11} & w_{12} & \ldots & w_{1 n} \\
w_{21} & w_{22} & \ldots & w_{2 n} \\
\vdots & \vdots & \ddots & \vdots \\
w_{p 1} & w_{p 2} & \ldots & w_{p n}
\end{array}\right]_{n \times p}
$$

Among them, for the index item $i, i=(1,2, \ldots n)$, the corresponding weight of the $P$-bit 
expert is:

$$
W i=(w i 1, w i 2, w i 3, \ldots, w i j, \ldots, w i p), j=(1,2, \ldots, p) \text {. }
$$

(1) Sort, reorder the weights in the index item $i$ from large to small, and get the $d_{i}$ :

$$
\begin{gathered}
\mathrm{W}_{\mathrm{i}} \Rightarrow \mathrm{D}_{\mathrm{i}} \\
=\left(\mathrm{d}_{\mathrm{i} 1}, \mathrm{~d}_{\mathrm{i} 2}, \ldots, \mathrm{d}_{\mathrm{ij}}, \ldots, \mathrm{d}_{\mathrm{ip}}\right)
\end{gathered}
$$

In formula, $d_{i 1} \leq d_{i 2} \leq \cdots \leq d_{i j} \leq \cdots \leq d_{i p}$.

(2)Identify the weighted vectors, Weighted vector $V_{i}$ by combination $C_{p-1}^{j-1}$ :

$$
\begin{gathered}
V_{i}=\left(v_{i 1}, v_{i 2}, \ldots, v_{i j}, \ldots, v_{i p}\right) \\
v_{i j}=\frac{c_{p-1}^{j-1}}{\sum_{j=1}^{p} C_{p-1}^{j-1}}=\frac{c_{p-1}^{j-1}}{2^{p-1}}
\end{gathered}
$$

(3) Calculte the comprehensive weights, for the index $i$, the absolute weight can be obtained by the formula. Other indicators agree, obtain absolute weight distribution $D$ : according to formula.

$$
\begin{gathered}
c_{i}=\sum_{j=1}^{p} v_{i j} d_{i j} \\
D=\left(c_{1}, c_{2}, \ldots, c_{i}, \ldots, c_{n}\right),
\end{gathered}
$$

(4) Relative weight of the calculated index

For the index $i$, the absolute weight of its brother nodes is $c_{j}, j=1,2, \ldots, k$ :

$$
w_{i}=\frac{c_{i}}{\sum_{j=1}^{k} c_{j}}
$$

The final weight $W$ of the expert decision-making group for the evaluation index is:

$$
W=\left(w_{1}, w_{2}, \ldots, w_{i}, \ldots, w_{n}\right)
$$

\subsection{Establish Green construction rating level}

Table 2. Evaluation Level and Description.

\begin{tabular}{ccc}
\hline grade & Grade Description & Value range \\
\hline Nonqualified & Do not meet the green construction standards & {$[0,60)$} \\
\hline One-Star & Meet the basic requirements of green & $\begin{array}{c}\text { construction } \\
{[60,72)}\end{array}$ \\
\hline Two-star & Beyond the overall green construction level & {$[72,85)$} \\
\hline Three-star & All the indicators have reached the high level of & {$[85,100]$} \\
\hline
\end{tabular}

Referring to the existing specifications and standards, the evaluation model divides divided into four grades as shown in Table 2. 


\section{Development of green construction evaluation platform based on BIM information technology}

The purpose of the platform development is to integrate the PDCA cycle evaluation process established above for better application in practice. Based on the advantages of BIM informatization, distributed technology is adopted to build a green construction evaluation platform. The platform is divided into three parts (green information collection, green construction evaluation, BIM visual decision analysis), among which the client-based visual decision analysis module is built in the early model based on BIM modeling software Revit, transforms the rvt model into a format for web page calling display through the BIMface cloud platform, and the model and business functions are developed through JavaScript.

The platform can realize the functions of green construction plan deployment, site information collection, information evaluation and evaluation results analysis, so that the process of green construction evaluation can operate on one platform, and greatly simplifies the operation process in the practical application. At the same time, the construction enterprises the possibility based on systematic dynamic optimization. The architecture of the platform is shown in Figure 2.

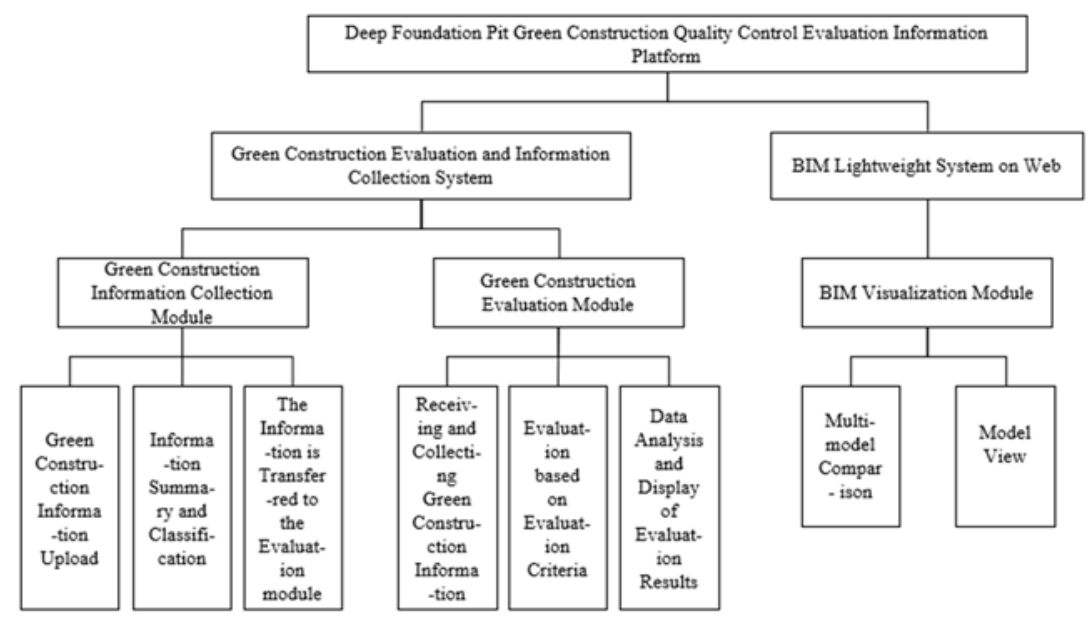

Fig. 2. Schematic of BIM Information Evaluation Platform.

\section{Example analysis}

This paper is verified by the Wuhan Yangtze River Shipping Center Project. The project is located in Jianghan Road business district, Wuhan, is a super high-rise building, large deep foundation pit; the east is less than 100 meters away from the Yangtze River, the rest of the historic houses, underground pipelines are complex and near the subway, the surrounding environment is extremely complex.

\subsection{Preparation of the preliminary green construction system plan}

First, the Project Department has formulated a preliminary system green construction scheme, as shown in Figure 3. 


\begin{tabular}{|c|c|c|c|}
\hline First level & \multicolumn{3}{|c|}{ The Target of Green construction } \\
\hline \multirow{3}{*}{$\begin{array}{l}\text { Environmental } \\
\text { protection }\end{array}$} & Sewage discharge & \multicolumn{2}{|c|}{$\begin{array}{l}\text { The water quality test is qualified, and the } \\
\qquad \mathrm{pH} \text { range is } 6-9\end{array}$} \\
\hline & Dust control & \multicolumn{2}{|c|}{$\begin{array}{l}\text { Dust height of foundation pit } \\
\text { excavation } \leq 1.5 \mathrm{~m}\end{array}$} \\
\hline & Noise control & \multicolumn{2}{|c|}{$\leq 70 \mathrm{~dB}$ on daytime and $\leq 55 \mathrm{~dB}$ at night } \\
\hline \multirow{7}{*}{$\begin{array}{l}\text { Material saving and } \\
\text { resource utilization }\end{array}$} & \multicolumn{3}{|c|}{$\begin{array}{l}\text { The loss rate of main materials is } 30 \% \text { lower than the rated loss } \\
\text { rate }\end{array}$} \\
\hline & Material name & Quota Loss & Target Loss \\
\hline & Steel bar & $4.5 \%$ & $0.8 \%$ \\
\hline & $\begin{array}{l}\text { Commercial } \\
\text { concrete }\end{array}$ & $1.5 \%$ & $0.7 \%$ \\
\hline & Masonry & $7 \%$ & $2 \%$ \\
\hline & Template & Turnover 6 times & Turnover 7 times \\
\hline & \multicolumn{3}{|c|}{ Obtaining raw material locally } \\
\hline \multirow{2}{*}{$\begin{array}{l}\text { Material saving and } \\
\text { resource utilization }\end{array}$} & \multicolumn{3}{|c|}{ Water consumption with output value of $10,000 ¥ \leq 65 \mathrm{kwh}$} \\
\hline & \multicolumn{3}{|c|}{ Electricity saving equipment allocation rate $\geq 90 \%$} \\
\hline \multirow{3}{*}{$\begin{array}{l}\text { Water saving and } \\
\text { utilization of water } \\
\text { resources }\end{array}$} & \multicolumn{3}{|c|}{$\begin{array}{l}\text { The water consumption of ten thousand yuan output value } \\
\text { should be controlled within } 2 \text { tons }\end{array}$} \\
\hline & \multicolumn{3}{|c|}{ Water saving equipment allocation rate $\geq 70 \%$} \\
\hline & \multicolumn{3}{|c|}{$\begin{array}{l}\text { Proportion of non municipal tap water utilization in total water } \\
\text { consumption } \geq 30 \%\end{array}$} \\
\hline $\begin{array}{l}\text { Land saving and } \\
\text { construction land } \\
\text { protection }\end{array}$ & \multicolumn{3}{|c|}{ Ratio of construction green land area to occupied land area } \\
\hline
\end{tabular}

Fig. 3. Preliminary Green Construction Scheme.

\subsection{Identification of index weight based on OWA operator}

Based on the AHP hierarchical analysis method of OWA operator optimization described above, the questionnaire results of 20 experts were calculated and determined six weights of "primary index $W$ ", "environmental protection $W A$ ", "construction management $W B$ ", "Save materials $W C$ ", "water saving $W D$ ", " energy conservation $W E$ ", "Land saving $W F^{\prime \prime}$.

$$
\begin{aligned}
& \mathrm{W}=[99.83,88.33,81.17,81,81.33,71.5] \\
& \mathrm{W}_{\mathrm{A}}=[99,92.67,61.17,72.83,83.67,83.83] \\
& \mathrm{W}_{\mathrm{B}}=[100,100,93.33,85,72.17] \\
& \mathrm{W}_{\mathrm{C}}=[98.5,96.33,71.33] \\
& \mathrm{W}_{\mathrm{D}}=[96,96.17,91.33,63.5] \\
& \mathrm{W}_{\mathrm{E}}=[92.5,74.33,63] \\
& \mathrm{W}_{\mathrm{F}}=[100,98.33,82.33]
\end{aligned}
$$

\subsection{Informatization evaluation based on PDCA cycle}

The weight calculation results are input into the evaluation system of the platform, and the preparation work of the platform has been completed, and then the platform is used to carry out the dynamic evaluation of green construction. Green construction information is collected through the information collection module, mainly including the documents, videos, pictures, inspection reports and interview records generated from the green construction activities.

Information evaluation is conducted based on the collected data. According to the total construction period of the project, it is divided into 50 equal parts. The experts conduct the evaluation in the evaluation system, and take 10 equiparts as the cycle to reflect the green construction level of this period, and provide a basis for the comparative analysis of the next stage. 
Next, it entered the action link in the PDCA cycle. After the completion of the last cycle, the construction enterprise learned which links of the current green construction based on the specific evaluation score of the completed cycle, and found potential problems to prepare for the deployment of the next cycle. At the same time, the content of the construction of the two cycles is different, and the influence factors of different cycles on the project are also different. Here, the construction enterprises need to make more detailed deployment based on the specific construction content of the next cycle. The BIM visualization decision analysis module can clearly present the increased construction content of the next cycle, and show it in a three-dimensional way. At the same time, the model construction tree function binds the green construction evaluation regulations, which can provide necessary reference for construction enterprises to formulate scientific and reasonable green construction plan, Green construction evaluation is a systematic project, how to develop the green construction scheme based on the evaluation regulations and make the construction enterprise with the most reasonable cost is the key to promote green construction in practical promotion and application, BIM visual decision analysis is shown in Figure 4.

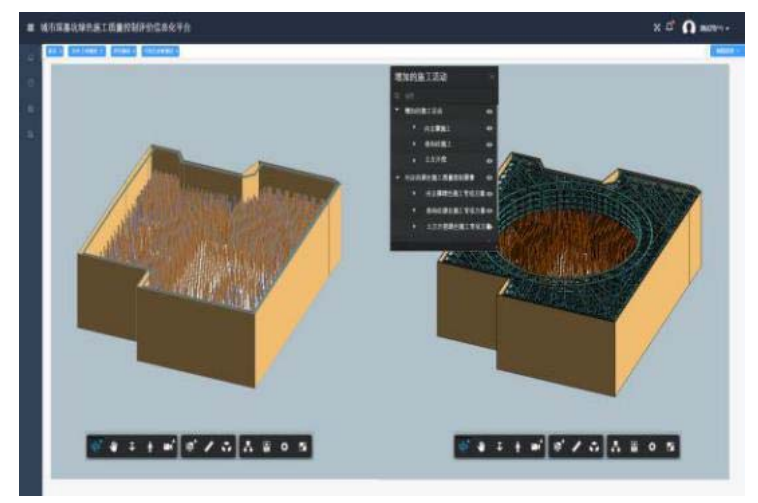

Fig. 4. The Visual Decision Analysis System.

After 2 years of accumulation, 50 equal evaluation analysis was completed, as shown in Figure 5.

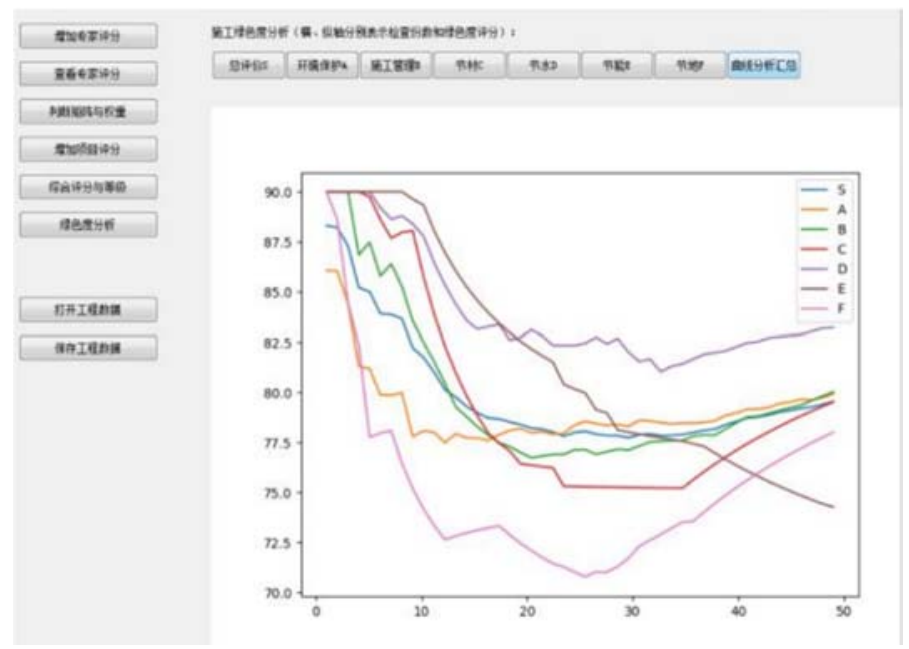

Fig. 5. Green Construction General Curve of the Project.

According to the curve analysis, the overall green construction level of the project 
declined in the early stage, This is due to the severe environmental damage in the early stage of deep foundation pit construction, Early score is more rare, In order to meet the project cost and construction period, Decide to reduce the investment in green construction; After the establishment of the deep foundation pit enclosure system is balanced, This is due to the weakened environmental impact of this stage, In order to make up for the shortage of green construction evaluation scores in the previous period, Increase the investment in green construction, Meet the regulations in the evaluation through local green construction measures, So the overall trend of this period is relatively gentle, And showed a slow rising trend; The later curve showed a rapid upward trend, This is due to, as the deep foundation pit becomes balanced with the environment, Construction companies were intended to balance their previous scores during this period, From the perspective of system engineering, If using the internal support hydrostatic cutting technology, The construction enterprise has achieved large scores in environmental protection, material saving and land saving, Realize the systematic improvement of the level of green construction.

\section{Conclusion and outlook}

Through scientific evaluation theory and quality control method, dynamic green construction evaluation established and realize the transition from theory to practice through BIM information technology development platform. Finally, case analysis proves that dynamic evaluation is beneficial to green construction and an innovative measure to promote sustainable development. At the same time, the decision-making analysis system in the platform still needs to be improved in terms of intelligence, and the actual use process requires a large number of artificial decision-making, which increases the time and the subjectivity is too strong. Targeted solutions need to be supplemented in subsequent studies.

\section{References}

1. Tian Tian. Research on Green Construction of Metro Engineering [J]. Technology Outlook, 2016,26 (3) $47-48$

2. Wang $\mathrm{Fu}, \mathrm{Su}$ Jie. Study on Evaluation Indicators and Model of Highway Green Construction Based on Negative Enropy Theory [J]. Highway, 2017 (4): 191-194.

3. Li Xiang, Liu Chang, Li Yinghui. Green Construction Evaluation of College Construction Engineering Based on gray-shapley [J]. Shanxi Construction, 2020,46 (8): 143-146

4. Su Huan, Tan Lixin, Li Aquatic, etc. Preliminary Exploration on the Green Construction Evaluation System of Metro Project Based on PDCA Cycle [J]. Journal of Hunan Institute of Engineering (Natural Sciences), 2020,30 (2): 84-90

5. Hong Yanyan. Green Construction Management Research Based on WSR [D]. Gansu: Lanzhou University of Technology, 2018

6. Ma Rongmin. Application Research on Green Construction Management Based on BIM Technology [D]. Guangxi: Guangxi University, 2016

7. Liu Zhao Haomin. Research on Green Construction Information Management Based on BIM and Knowledge Management [D]. Hubei: Wuhan University, 2019. 